\title{
Exploring Tetrathiafulvalene-Carbon Nanodots Conjugates in Charge Transfer Reactions
}

\author{
Andrés Ferrer-Ruiz, ${ }^{[a]}$ Tobias Scharl, ${ }^{[b]}$ Philipp Haines, ${ }^{[b]}$ Laura Rodríguez-Pérez, ${ }^{[a]}$ Alejandro \\ Cadranel, ${ }^{[b]} M^{a}$ Ángeles Herranz, ${ }^{*[a]}$ Dirk M. Guldi, ${ }^{*[b]}$ and Nazario Martín ${ }^{*[a, c]}$
}

This work is dedicated to Prof. Klaus Müllen on the occasion of his $70^{\text {th }}$ birthday

\begin{abstract}
Carbon nanodots (CNDs) have been synthesized using low-cost and biocompatible starting materials such as citric acid/urea under microwave irradiation and constant pressure conditions. The obtained pressure synthesized CNDs (pCND) were covalently modified with photo- and electro-active $\pi$-extended tetrathiafulvalene (exTTF) by means of a two-step esterification reaction affording pCND-exTTF. The electronic interactions between the CNDs and exTTF were investigated in the ground and excited states. Ultrafast pump-probe experiments assisted in corroborating that charge separation governs the deactivation of photoexcited pCND-exTTF. These size-regular structures, as revealed by AFM, are stable electron donor-acceptor conjugates of interest for a better understanding of basic processes such as artificial photosynthesis, catalysis and photovoltaics, involving readily available fluorescent nanodots.
\end{abstract}

Carbon nanodots (CNDs) have emerged as intriguing lightabsorbing nanomaterials as alternatives to traditional semiconductor quantum dots and organic chromophores owing to their unique photophysical properties, photo-chemical stability, and biocompatibility. ${ }^{[1-6]}$ In terms of CNDs production, laser ablation, ${ }^{[7]}$ acidic oxidation, ${ }^{[8]}$ hydrothermal methods, ${ }^{[9]}$ ultrasound or microwave-assisted synthesis, ${ }^{[10,11]}$ and electrochemical techniques stand out. ${ }^{[12]}$ A number of "green" routes have also been explored to prepare CNDs in a single step from affordable starting materials and without needing elaborated experimental set-ups. ${ }^{[3,13]}$ As a leading example, nitrogen-containing precursors should be mentioned. ${ }^{[14-16]}$ Their use has resulted in CNDs, which feature emission efficiencies almost as high as fluorescent dyes, ${ }^{[1,17,18]}$ despite the lack of a complete understanding of its origin and/or nature.

CNDs combine properties such as good UV-Vis light absorption, water solubility and high stability, which hold a great promise for their implementation as photosensitisers for solardriven catalysis and in charge-transfer assays for artificial

[a] Mr. A. Ferrer-Ruiz, Dr. L. Rodríguez-Pérez, Dr. M. A. Herranz, Prof. Dr. N. Martín

Departamento de Química Orgánica I, Facultad de Ciencias

Químicas, Universidad Complutense de Madrid, 28040 Madrid,

Spain

E-mail: maherran@ucm.es, nazmar@ucm.es

[b] Mr. T. Scharl, Mr. P. Haines, Dr. A. Cadranel, Prof. Dr. D. M. Guldi Department of Chemistry and Pharmacy, Interdisciplinary Center for Molecular Materials, University of Erlangen, Egerlandstr. 3, 91058 Erlangen, Germany

E-mail: dirk.guldi@fau.de

[c] Prof. Dr. N. Martín

IMDEA-Nanociencia, C/ Faraday, 9, Campus de Cantoblanco, E28049 Madrid, Spain

Supporting information for this article can be found under: https://doi.org/10.1002/anie.xxxxxxxxxxx photosynthesis. ${ }^{[1,19]}$ However, CNDs have been subject of just a few photoinduced charge transfer studies. By virtue of variable supramolecular forces either electron donors or acceptors have been non-covalently combined with CNDs. ${ }^{[16,20-23]}$ The covalent decoration of CNDs with photo- and electro-active building blocks has only recently been explored with porphyrins, ${ }^{[24]}$ where the strong electronic interaction with CNDs results in a series of energy transfer and charge separation events. ${ }^{[25]}$

The covalent approach to CNDs functionalization is particularly interesting as it enables the introduction of multiple photo- or electro-active units in the form of stable nanoconjugates. In this context, we have explored the preparation of novel CND-based electron donor-acceptor systems. In particular, we have covalently linked a photo- and redox-active molecular building block, namely m-extended tetrathiafulvalene (exTTF), ${ }^{[26]}$ to CNDs materials. exTTFs are pro-aromatic electron donors. Unlike porphyrins, they undergo a remarkable gain of aromaticity and planarity upon oxidation, forming stable one-electron and two-electron oxidized species at relatively low oxidation potentials. Considering these features, exTTFs have been widely used to form electroactive architectures when linked to fullerenes, carbon nanotubes, and graphene. ${ }^{[27]}$ They have been successfully used for preparing photoinduced electron transfer systems ${ }^{[28]}$ as well as solar energy conversion devices. ${ }^{[29]}$

We have synthesized the starting CNDs by using citric acid and urea precursors by following the recently published protocol by some of us. ${ }^{[20-23]}$ A constant pressure during the microwave synthesis leads to a distribution of pressure synthesized CNDs (pCND) with a sharp and narrow emission pattern. ${ }^{[2]}$ To probe these pCND in terms of intramolecular charge transfer events we modified them with exTTF (Figure 1). The as-prepared pCND were treated with thionyl chloride under heating conditions to convert the carboxylic acids to acid chlorides. These reacted in situ with 2-hydroxymethyl-exTTF ${ }^{[30]}$ to yield pCND-exTTF, by following a procedure similar to those previously reported. ${ }^{[31,32]}$ In a control experiment, acid chloride pCNDs (pCND-Cl) were isolated and subsequently hydrolysed back to the starting carbon nanodots (pCND-H). Analysis of these materials by different techniques (TGA, FTIR and NMR) demonstrated that the pCND core is not subject to significant modification of its structure during the $24 \mathrm{~h}$ treatment with thionyl chloride (Figures S6, S7, S9 and S12). The obtained pCND-exTTF were fully characterized and complete details regarding syntheses and analyses (TEM, AFM, NMR, TGA, XRD, mass spectrometry, FTIR, Raman and XPS) can be found in the Supporting Information (Figures S1-S5 and S8-S15).

From TEM we concluded the presence of pCND-exTTF, which are, however, prone to aggregate on the grid; smaller individual pCND-exTTF coexist with larger objects (Figure S1). A more homogeneous distribution with an average size of $5.3 \pm$ 
$1.9 \mathrm{~nm}$ was found in AFM images taken on mica substrates. Only a few aggregates were discernable (Figure S3). Matrix assisted laser desorption ionization-time of flight (MALDI-TOF) displayed a MW dispersion centered at $2000 \mathrm{Da}$, in accordance with the presence of a polydisperse nanomaterial of the estimated size of the pCND-exTTF. The presence of the exTTFs was corroborated by the fragmentation pattern observed at 410 Da (Figure S11).

Support for the covalent functionalization of the pCND was gathered from ${ }^{1} \mathrm{H}$ and ${ }^{13} \mathrm{C}$ NMR (Figures S4 and S5), which showed mainly the signals corresponding to the 1,3-dithiole rings at $6.7 \mathrm{ppm}\left({ }^{1} \mathrm{H}\right)$ and $118.0-118.2 \mathrm{ppm}\left({ }^{13} \mathrm{C}\right)$ as well as the anthracene core at 7.3-7.8 ppm $\left({ }^{1} \mathrm{H}\right)$ and $120.7-140.7 \mathrm{ppm}\left({ }^{13} \mathrm{C}\right)$. As a result of pCND functionalization, the signal corresponding to the hydroxy group of the 2-hydroxymethyl-exTTF dissappers in the ${ }^{1} \mathrm{H}$ NMR spectrum of pCND-exTTF. Please note that this signal is present as a triplet at ca. $5.3 \mathrm{ppm}$ in the exTTF reference (Figure S4). Some of the pCND NMR signals are not observed in the pCND-exTTF spectra. A likely rationale infers that the corresponding groups are entrapped within the pCND core or that their signals are either very broad or invisible due to the restricted mobility of such groups in this environment. ${ }^{[3,34]}$ Finally, $1 \mathrm{H}$ diffusion ordered NMR spectroscopy (DOSY) of pCND-exTTF (Figure S8) enables only the detection of species with diffusion coefficients of $D \approx 3 \times 10^{-10} \mathrm{~m}^{2} / \mathrm{s}$, which is in accordance with related previous results. ${ }^{[23,24]}$

From TGA under inert atmosphere a similar weight loss is observed for both pCND and pCND-exTTF, although the stability of the CNDs seems to increase upon esterification. Furthermore, powder XRD shows for pCND-exTTF a broad diffraction consistent with a nanocrystalline graphitic structure (Figure S10). The Raman spectra of pCND and pCND-exTTF also reveal graphitic content and defects, since both $G$ and Dband are observed. (Figure S13). From FTIR spectroscopy (Figure S12), the typical stretching vibrations of $\mathrm{C}=\mathrm{O}, \mathrm{C}-\mathrm{N}$, and C-O of pCND-exTTF are distinguished at 1715-1633, 1401, and $1090-1018 \mathrm{~cm}^{-1}$, respectively. In addition, stretching vibrations of $\mathrm{O}-\mathrm{H}$ and $\mathrm{N}-\mathrm{H}$ evolve around $3430-3182 \mathrm{~cm}^{-1}$, while aliphatic $\mathrm{C}-\mathrm{H}$ bond stretching vibrations are discernible at $2925-2852 \mathrm{~cm}^{-1}$.

XPS was also found to be useful in terms of deriving structural information from pCND and pCND-exTTF (Figure 1, Figures S8 and S9 and Table S1). In addition to contributions stemming from the core levels of $\mathrm{C} 1 \mathrm{~s}, \mathrm{~N} 1 \mathrm{~s}$, and $\mathrm{O} 1 \mathrm{~s}$, evidence for the $S 2 p$ core level were noted for pCND-exTTF in Figure $S 9$ This confirmed the presence of sulfur in PCND-exTTF, ${ }^{[35]}$ which was not found for the as-prepared pCND prior to the reaction with exTTF. Deconvolution of the $C$ 1s core-level region of pCND-exTTF points to six species with binding energies of $284.1 \mathrm{eV}(\mathrm{C}-\mathrm{C} / \mathrm{C}=\mathrm{C}), 284.9 \mathrm{eV}(\mathrm{C}-\mathrm{O} / \mathrm{C}-\mathrm{N}), 286.2 \mathrm{eV}(\mathrm{C}-\mathrm{O}-\mathrm{C})$, 287.4( $\mathrm{C}=\mathrm{O}), 288.2(\mathrm{O}-\mathrm{C}=\mathrm{O})$, and $289.7 \mathrm{eV}\left(\pi-\pi^{*}\right.$ shake up). ${ }^{[36]}$

The same components were used to fit the $C$ 1s core-level region in pCND (Figure S8). The presence of the characteristic $\pi-\pi^{*}$ shake up of carbon atoms in graphene-like structures ${ }^{[37]}$ is in agreement with the TGA and Raman analyses and prompts to some graphitic character of the CND materials. TEM and AFM further supports the notion of $\pi-\pi^{*}$ shake up bands since the presence of small aggregates together with individual pCND are observed (Figures S2 and S3). The fit of the N 1s line of pCNDexTTF shows four different chemical components centered at $398.5 \mathrm{eV}$ (pyridinic N), $399.3 \mathrm{eV}$ (amine), $400.0 \mathrm{eV}$ (pyrrolic N), and $401.0 \mathrm{eV}$ (graphitic $\mathrm{N}$ ). ${ }^{[14,24]}$ The ratios of the same components in pCND suggest a slight increase of graphitic and pyridinic nitrogen after functionalization with exTTF, which goes along with the TGA results.
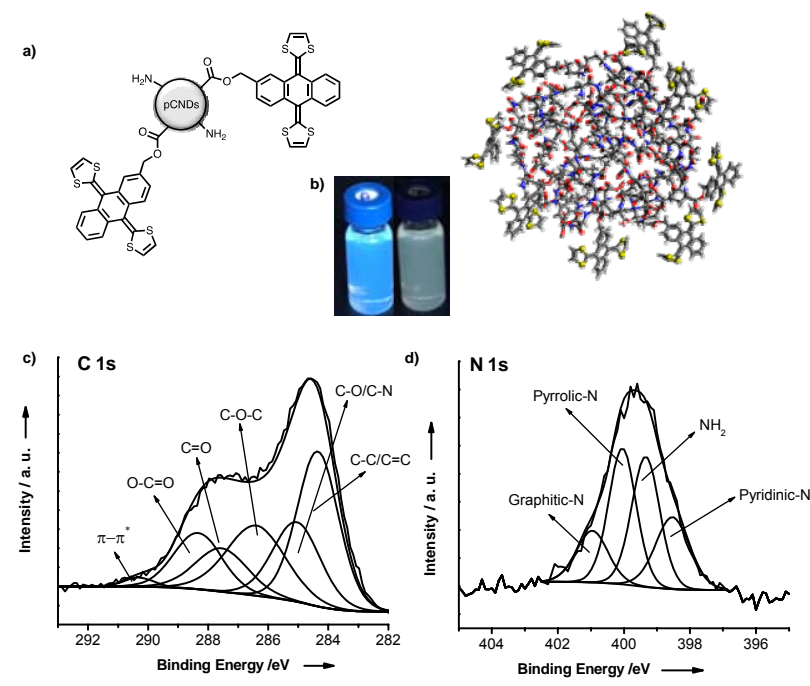

Figure 1. a) Schematic illustration of pCND-exTTF. Color code: $S$ (yellow), N (blue), $\mathrm{O}$ (red), C (grey) and $\mathrm{H}$ (white). b) Water solutions of pCND (left) and pCND-exTTF (right) under $365 \mathrm{~nm}$ light illumination. c) XPS deconvoluted $C$ 1s spectrum of pCND-exTTF. d) XPS deconvoluted N 1s spectrum of pCNDexTTF.

All the different building blocks, that is, pCND and exTTF, are discernable in the absorption spectrum of pCND-exTTF (Figure 2). The exTTF-centered maxima are observed in both cases at 368 and $432 \mathrm{~nm}$. Additionally, the absorption tails due to the presence of pCND throughout the visible range of the solar spectrum is also observed.

pCND-exTTF exhibits the characteristic quasi-reversible oxidation of exTTF (Figure 2 and Figure S16) at $+0.01 \mathrm{~V}$ vs. $\mathrm{Ag} / \mathrm{AgNO}_{3}$ in DMSO that is in accordance with an exTTF reference. $^{[38]}$ pCND show two irreversible oxidations corresponding to the amino groups at -0.01 and $0.58 \mathrm{~V}$ and several irreversible reductions at $-1.30,-1.72,-2.03$ and $-2.31 \mathrm{~V}$ (Figure 2 and Figure S10). ${ }^{[23]}$ After exTTF modification, the electrochemical features of pCND are not clearly discernible and mostly the exTTF oxidation (see above) and the reduction of its skeleton, in the form of two irreversible reductions close to the solvent window ( -2.41 and $-2.53 \mathrm{~V})$, are observed.

First insights into excited-state interactions came from fluorescence measurements. Here, we noted a pCND fluorescence quenching of at least a $90 \%$ in pCND-exTTF as shown in Figure 3 . Based on this finding, we postulate the presence of an additional pCND excited state deactivation in pCND-exTTF; the presence of photo- and electro-active exTTF activates either an energy or a charge transfer process.

Unambiguous proof for a charge transfer rather than an energy transfer deactivation stemmed from femtosecond transient absorption measurements with pCND-exTTF. In particular, $387 \mathrm{~nm}$ excitation leads to the instantaneous formation of an excited state with prominent maxima and minima at 612 and $438 \mathrm{~nm}$, respectively. These transform, in contrast to that observed for the exTTF and pCND references, within a few picoseconds into a new transient. The most notable fingerprints of this transient are maxima at 463,549 , and $660 \mathrm{~nm}$ as well as a $423 \mathrm{~nm}$ minimum, which are in sound agreement with pulse radiolytic findings focusing on the oxidation of exTTFs. ${ }^{[39-41]}$ In 
other words, a charge separation, in which exTTF are oneelectron oxidized and pCND are one-electron reduced, evolves upon formation of the initial excited state. The ultimate fate of the pCND"-exTTF $^{*+}$ charge separated state is charge recombination on the timescale of tens of picoseconds and the product is the ground state. Analyses, which were based both on multi-wavelength and global methods, provided the means to derive lifetimes of the charge separation and charge recombination processes.
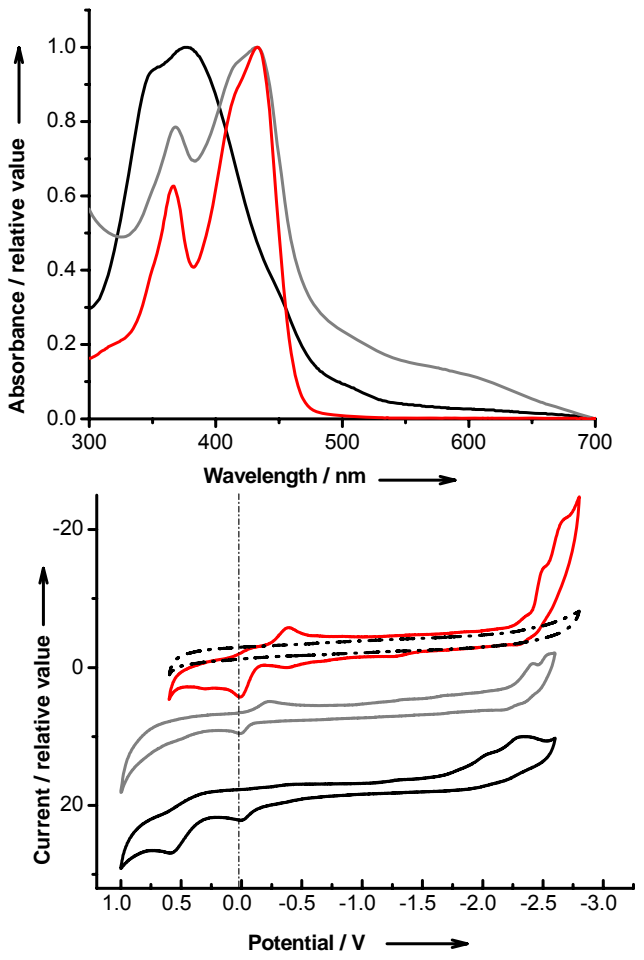

Figure 2. a) UV-Vis absorption spectra of pCND (black), exTTF (red) and pCND-exTTF (grey) in DMSO solutions. b) Cyclic voltammograms of an exTTF reference (red), pCND-exTTF (grey), and pCND (black) in DMSO solutions containing $0.1 \mathrm{M} \mathrm{TBAPF}_{6}$ as supporting electrolyte with a glassy carbon working electrode, a $\mathrm{Ag} / \mathrm{AgNO}_{3}$ reference electrode, and a Pt wire counter electrode. The dashed line represents the background signal.

Multi-wavelength analyses proof that the charge separation as well as charge recombination in pCND-exTTF are fast with 1.3 and $13.3 \mathrm{ps}$, respectively. As a consequence, we turned to global target analysis and employed a kinetic model based on an ultrafast chirp correction as well as monophasic charge separation and charge recombination - Figure 4. The spectral features of the species associated spectra (SAS) are in sound agreement with the proposed kinetic model, that is, a laser chirp (SAS1), an exTTF based excited state (SAS2), and a pCND“exTTF $^{*+}$ charge separated state (SAS3).
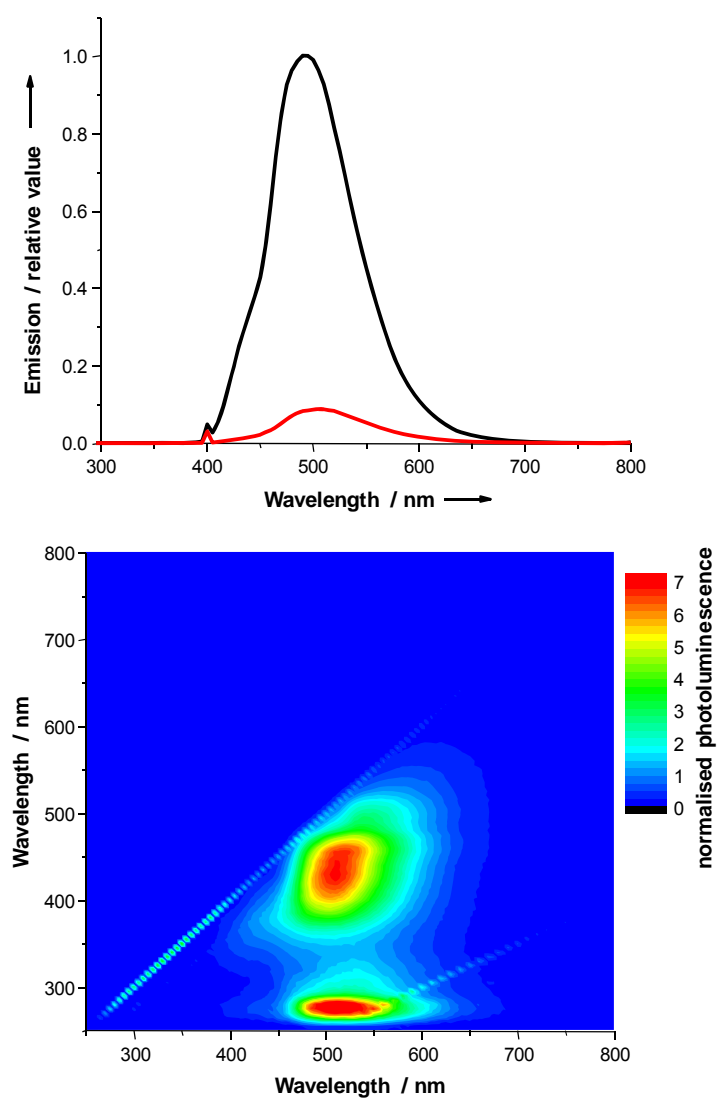

Figure 3. Upper part - steady state emission spectra of iso absorbing pCND (black) and pCND-exTTF (red) obtained at an excitation of $400 \mathrm{~nm}$ at $295 \mathrm{~K}$ in DMSO. Lower part - excitation/emission 3D map for pCND-exTTF obtained at $295 \mathrm{~K}$ in DMSO.

In conclusion, we have carried out the synthesis of blue-light emitting CNDs from a mixture of citric acid/urea under microwave pressure controlled conditions. The obtained pCND were treated with thionyl chloride to create acyl chloride groups on the CNDs surface that react immediately with 2hydroxymethyl derivatives of exTTF. Characterization of pCNDexTTF by TEM, AFM, NMR, TGA, XRD, mass spectrometry, FTIR, Raman, XPS, UV-Vis and cyclic voltammetry, confirms the covalent anchoring of exTTF to the CND core. The electronic communication between the electron accepting pCND and the electron donating exTTFs has been investigated by a variety of photophysical techniques. Remarkably, pump-probe experiments reveal that charge transfer dominates the deactivation of photoexcited exTTF in pCND-exTTF. Our experimental findings reveal that the synthetic method for the preparation of PCND is highly reproducible, providing stable and readily available fluorescent nanodots. pCND are photo- as well as electro-active species and are of interest in a variety of fields, namely artificial photosynthesis, catalysis and photovoltaics, where photoinduced electron transfer processes play a key role. Work is currently in progress in these directions. 


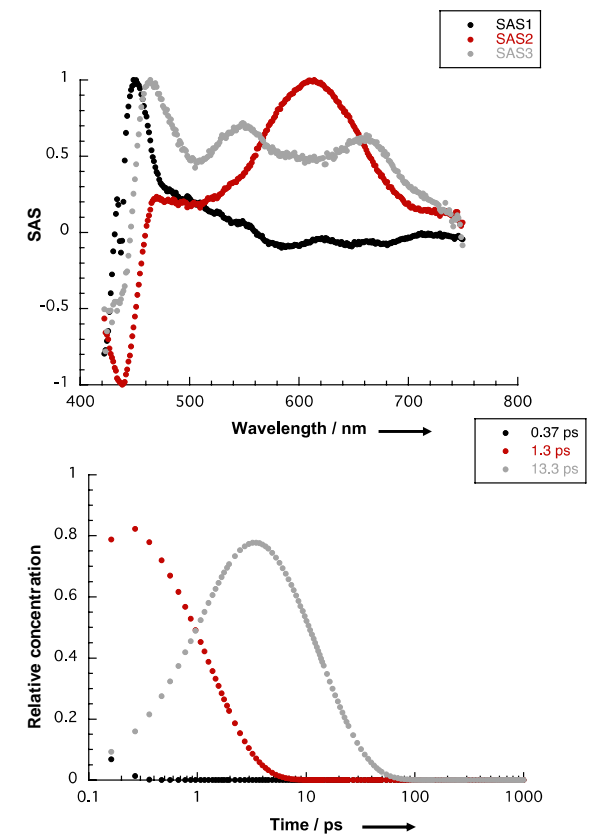

Figure 4. Upper part - normalized species associated transient absorption spectra (SAS1, SAS2, and SAS3) for pCND-exTTF obtained at $295 \mathrm{~K}$ in DMSO using the kinetic model described above. Lower part - corresponding concentration profiles for pCND-exTTF.

\section{Acknowledgements}

Financial support from the European Research Council (ERC320441-Chiralcarbon), the Ministerio de Economía y Competitividad (MINECO) of Spain (Projects CTQ2014-52045-R, CTQ2015-71936-REDT and CTQ2016-81911-REDT), and the CAM (PHOTOCARBON project S2013/MIT-2841) is acknowledged. This work was also funded by the Deutsche Forschungsgemeinschaft as part of the Excellence Cluster Engineering of Advanced Materials and SFB 953 Synthetic Carbon Allotropes as well as by the Bavarian State Government as part of the Solar Technologies go Hybrid initiative.

Keywords: carbon nanodots $\bullet$ tetrathiafulvalene $\cdot$ donoracceptor systems $\bullet$ excited state dynamics $\bullet$ charge-transfer

[1] G. A. M. Hutton, B. C. M. Martindale, E. Reisner, Chem. Soc. Rev. 2017 46, 6111-6123

[2] A. Cayuela, M. L. Soriano, C. Carrillo-Carrión, M. Valcárcel, Chem Commun. 2016, 52, 1311-1326.

[3] X. T. Zheng, A. Ananthanarayanan, K. Q. Luo, P. Chen, Small 2015, 11 , 1620-1636.

[4] S. Y. Lim, W. Shen, Z. Gao, Chem. Soc. Rev. 2015, 44, 362-381.

[5] Y. Wang, A. Hu, J. Mater. Chem. C 2014, 2, 6921-6939.

[6] H. Li, Z. Kang, Y. Liu, S.-T. Lee, J. Mater. Chem. A 2012, 22, 24230 24253

[7] H. P. S. Castro, V. S. Souza, J. D. Scholten, J. H. Dias, J. A. Fernandes, F. S. Rodembusch, R. dos Reis, J. Dupont, S. R. Teixeira, R. R. B. Correia, Chem. Eur. J. 2016, 22, 138-143.

[8] R. Sekiya, Y. Uemura, H. Murakami, T. Haino, Angew. Chem. 2014, 126 , 5725-5729; Angew. Chem. Int. Ed. 2014, 53, 5619-5623.

[9] Z.-C. Yang, M. Wang, A. M. Yong, S. Y. Wong, X.-H. Zhang, H. Tan, A. Y. Chang, X. Li, J. Wang, Chem. Commun. 2011,47, 11615-11617.

[10] T. T. Meiling, P. J. Cywiński, I. Bald, Sci. Reports, 2016, 6, 28557.

[11] H. Zhu, X. Wang, Y. Li, Z. Wang, F. Yang, X. Yang, Chem. Commun. 2009, 5118-5120.

[12] X. Tan, Y. Li, X. Li, S. Zhou, L. Fan, S. Yang, Chem. Commun. 2015, 51 , 2544-2546.

[13] J. Wang, C.-F. Wang, S. Chen, Angew. Chem. 2012, 124, 9431-9435; Angew. Chem. Int. Ed. 2012, 51, 9297-9301.
[14] F. Arcudi, L. Đorđević, M. Prato, Angew. Chem. 2017, 129, 4234-4237 Angew. Chem. Int. Ed. 2017, 56, 4170-4173.

[15] S. Carrara, F. Arcudi, M. Prato, L. De Cola, Angew. Chem. 2017, 129 4835-4839; Angew. Chem. Int. Ed. 2017, 56, 4757-4761.

[16] B. C. M. Martindale, G A. M. Hutton, C. A. Caputo, S. Prantl, R. Godin, J. R. Durrant, E. Reisner, Angew. Chem. 2017, 129, 6559-6563; Angew. Chem. Int. Ed. 2017, 56, 6459-6463.

[17] D. Mazzier, M. Favaro, S. Agnoli, S. Silvestrini, G. Granozzi, M. Maggini, A. Moretto, Chem. Commun. 2014, 50, 6592-6595.

[18] S. Zhu, Q. Meng, L. Wang, J. Zhang, Y. Song, H. Jin, K. Zhang, H. Sun, H. Wang, B. Yang, Angew. Chem. 2013, 125, 4045-4049; Angew. Chem. Int. Ed. 2013, 52, 3953-3957.

[19] a) S. Fukuzumi, K. Ohkubo, T. Suenobu, Acc. Chem. Res. 2014, 47 1455-1464; b) A. Listorti, J. Durrant, J. Barber, Nature Materials 2009, 8 929-930.

[20] V. Strauss, J. T. Margraf, C. Dolle, B. Butz, T. J. Nacken, J. Walter, W. Bauer, W. Peukert, E. Spiecker, T. Clark, D. M. Guldi, J. Am. Chem. Soc. 2014, 136, 17308-17316.

[21] V. Strauss, J. T. Margraf, K. Dirian, Z. Syrgiannis, M. Prato, C. Wessendorf, A. Hirsch, T. Clark, D. M. Guldi, Angew. Chem. 2015, 127, 8410-8415; Angew. Chem. Int. Ed. 2015, 54, 8292-8297.

[22] V. Strauss, J. T. Margraf, T. Clark, D. M. Guldi, Chem. Sci. 2015, 6, 68786885

[23] V. Strauss, A. Kahnt, E. M. Zolnhofer, K. Meyer, H. Maid, C. Placht, W. Bauer, T. J. Nacken, W. Peukert, S. H. Etschel, M. Halik, D. M. Guldi, Adv. Funct. Mater. 2016, 26, 7975-7985.

[24] F. Arcudi, L. Đorđević, M. Prato, Angew. Chem. 2016, 128, 2147-2152 Angew. Chem. Int. Ed. 2016, 55, 2107-2112.

[25] F. Arcudi, V. Strauss, L. Đorđević, A. Cadranel, D. M. Guldi, M. Prato, Angew. Chem. 2017, 129, 12265-12269; Angew. Chem. Int. Ed. 2017, 56, 12097-12101.

[26] F. G. Brunetti, J. L. López, C. Atienza, N. Martín, J. Mater. Chem. 2012 22, 4188-4205.

[27] a) G. Bottari, M. A. Herranz, L. Wibmer, M. Volland, L. Rodríguez-Pérez, D. M. Guldi, A. Hirsch, N. Martín, F. D'Souza, T. T. Torres, Chem. Soc Rev. 2017,46, 4464-4500; b) K. Dirian, M. A. Herranz, G. Katsukis, J. Malig, L. Rodríguez-Pérez, C. Romero-Nieto, V. Strauss, N. Martín, D. M. Guldi, Chem. Sci. 2013, 4, 4335-4353; c) N. Martín, L. Sánchez, M. A Herranz, B. Illescas, D. M. Guldi, Acc. Chem. Res. 2007, 40, 1015-1024.

[28] a) J. López-Andarias, M. J. Ródríguez, C. Atienza, J. L. López, T. Mikie, S Casado, S. Seki, J. L. Carrascosa, N. Martín, J. Am. Chem. Soc. 2015 137, 893-897; b) A. Insuasty, C. Atienza , J. L. López, J. Marco-Martínez S. Casado, A. Saha, D. M. Guldi, N. Martín, Sci. Rep. 2015, 5, 14154; c) J. López-Andarias, J. L. López, C. Atienza, F. G. Brunetti, C. Romero-Nieto, D. M. Guldi, N. Martín, Nat. Commun. 2014, 5, 3763; d) F. G. Brunetti, C. Romero-Nieto, J. López-Andarias, C. Atienza, J. L. López, D. M. Guldi, N. Martín, Angew. Chem. 2013, 125, 2013, 2236-2240; Angew. Chem. Int. Ed. 2013, 52, 2180-2184.

[29] S. Wenger, P.-A. Bouit, Q. Chen, J. Teuscher, D. Di Censo, R. HumphryBaker, J.-E. Moser, J. L. Delgado, N. Martín, S. M. Zakeeruddin, M. Grätzel, J. Am. Chem. Soc. 2010, $132,5164-5169$.

[30] G. J. Marshallsay, M. R. Bryce, J. Org. Chem. 1994, 59, 6847-6849.

[31] G. A. M. Hutton, B. Reuillard, B. C. M. Martindale, C. A. Caputo, C. W. J. Lockwood, J. N. Butt, E. Reisner, J. Am. Chem. Soc. 2016, 138, 1672216730.

[32] C. Liu, L. Bao, B. Tang, J.-Y. Zhao, Z.-L. Zhang, L.-H. Xiong, J. Hu, Small 2016, 34, 4702-4706.

[33] A. Muñoz, B. M. Illescas, J. Luczkowiak, F. Lasala, R. Ribeiro-Viana, J. Rojo, R. Delgado, N. Martín, J. Mater. Chem. B 2017, 5, 6566-6571.

[34] G. M. Soliman, J. Szychowski, S. Hanessian, F. M. Winnik, Soft Matter 2010, 6, 4504-4514

[35] J. Zhou, G. Tian, Y. Chen, Y. Shi, C. Tian, K.i Pan, H. Fu, Sci. Rep. 2014 4, 4027.

[36] T. I. T. Okpalugo, P. Papakonstantinou, H. Murphy, J. McLaughlin, N.M.D. Brown, Carbon, 2005, 43, 153-161.

[37] D. García, L. Rodríguez-Pérez, M. A. Herranz, D. Peña, E. Guitián, S. Bailey, Q. Al-Galiby, M. Noori, C. J. Lambert, D. Pérez, N. Martín, Chem. Commun. 2016, 52, 6677-6680

[38] J. Mateos-Gil, L. Rodríguez-Pérez, M. Moreno Oliva, G. Katsukis, C Romero-Nieto, M. A. Herranz, D. M. Guldi, N. Martín, Nanoscale, 2015, 7 , 1193-1200.

[39] D. M. Guldi, L. Sánchez N. Martín, J. Phys. Chem. B, 2001, 105, 71397144

[40] M. A. Herranz, C. Ehli, S. Campidelli, M. Gutiérrez, G. L. Hug, K. Ohkubo, S. Fukuzumi, M. Prato, N. Martín, D. M. Guldi, J. Am. Chem. Soc. 2008, 130, 66-73.

[41] V. Strauss, A. Roth, M. Sekita, D M. Guldi, Chem 2016, 1, 531-556. 


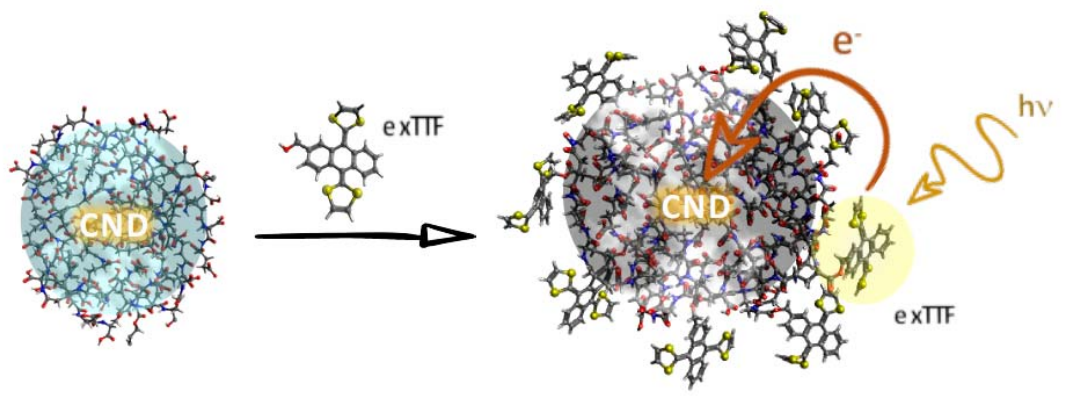

A. Ferrer-Ruiz, T. Scharl, P. Haines, L. Rodríguez-Pérez, A. Cadranel, M. A. Herranz, ${ }^{\star} D-M$. Guldi, ${ }^{*}$. Martín*

Page No. - Page No.

Exploring Tetrathiafulvalene-Carbon Nanodots Conjugates in Charge Transfer Reactions

Carbon nanodots (CNDs) are functionalized for the first time with $\pi$-extended tetrathiafulvalene (exTTF) units by using a covalent synthetic approach. Upon photoexcitation, a charge separated state with a lifetime in the range of ps evolves from electron donoracceptor interactions between the carbon nanodots and the electron-donating exTTF. 